\title{
Quality Assurance for Operating Room Illumination through Lean Six Sigma
}

\author{
Yucel Ozturkoglu \\ Department of Logistics Management, \\ Yasar University, Universite Caddesi, No: 37-39, Bornova, Izmir, Turkey. \\ E-mail: yucel.ozturkoglu@yasar.edu.tr \\ Yigit Kazancoglu \\ Department of Logistics Management, \\ Yasar University, Universite Caddesi, No: 37-39, Bornova, Izmir, Turkey. \\ Corresponding author: yigit.kazancoglu@ yasar.edu.tr \\ Muhittin Sagnak \\ Department of Information Management, \\ Izmir Kâtip Celebi University, Balatcik Kampusu, 35620, Cigli, Izmir, Turkey. \\ E-mail: muhittin.sagnak@ikcu.edu.tr \\ Jose Arturo Garza-Reyes \\ Center for Supply Chain Improvement, \\ The University of Derby, Kedleston Road Campus, Derby, DE22 1GB, UK. \\ E-mail: j.reyes@derby.ac.uk
}

(Received on December 9, 2020; Accepted on February 14, 2021)

\begin{abstract}
Since every mistake made in the healthcare industry can cause permanent harm or even death, some fundamental requirements should be considered when planning and designing operating rooms. Lighting is one of the most important ergonomic factors, especially for operating rooms. This paper investigates the integration of the lean approach and six sigma in measuring the efficiency of LED technology, which can also be regarded as a factor affecting the operating room efficiency. Measurement System Analysis (MSA) and Gage Control methods were applied to determine measurement variability in operating room illumination measurement process. Repeatability and reproducibility $(\% \mathrm{R} \& \mathrm{R})$ was found $12.89 \%$. After calibration, $\%$ R\&R value was found $8.21 \%$, which implies that calibration helped reduce variability.
\end{abstract}

Keywords- Operating rooms, Lighting, Lean approach, Six sigma, Measurement system analysis, Gage control.

\section{Introduction}

Although today's health technologies are advancing, there is a still relationship between patient health and the performance of the surgery in the healthcare system. Due to the fact that, any failure or mistake in the healthcare system can cause irrevocable and devastating damages on patients individually and groups alike as lives and quality of life are at risk (Ahmed et al., 2019). Therefore, in the healthcare sector, providing safe, reliable and affordable care while improving efficiency and performance remains a challenge (Brackett et al., 2013; Deblois and Lepanto, 2016; Hallam and Contreras, 2018). It is necessary to cooperate with a multidisciplinary approach to enhance both the quality and performance of the work done by surgery. The workplaces are one of the key elements for increasing the job performance of the surgeon. Engineers, designers, architectures, 
ergonomists, employees of the health sector need to be in close co-operation for designing operating room (OR) (Griefahn, 1992; Ibrahim et al., 2017; Krupka and Sandberg, 2006).

OR is the greatest cost and revenue center for the hospitals (Fong et al., 2016; Macario et al., 1995; Stahl et al., 2006) therefore, they have important impacts on the hospital performance (Azouz et al., 2019; Cardoen et al., 2010). Nowadays, improving OR efficiency plays a key role in hospital performance, because the financial management of health industry transforms into a challenging environment. Despite these challenges, Lean is promoted by healthcare professionals and policy makers to maximize value, minimize waste and decrease costs, as other sectors have done (Cookson et al., 2011; D'Andreamatteo et al., 2015; Hallam and Contreras, 2018; Teich and Faddoul, 2013). In addition, various factors affect the efficiency of the operating room, such as infrastructure, human resource management activities, variations in the schedules, processes, and the technology, and the limitations of the information management (Fairley et al., 2019). Besides these factors, ergonomic design is relevant to furniture safety, efficient layout design, user-friendliness of equipment and machines. It is not only limited to the equipment and machines that doctors use, but lighting is also important for ergonomic attributes because there is a fact that almost $80 \%$ of external stimuli affect eyes (Budhiraja, 2010). Thus, lighting within the OR is considered as crucial for the performance of the tasks and is a critical feature for an OR (Aganovic et al., 2017; Refaie et al., 2017; Seagull, 2012).

One of the research areas for services based on lean thinking is the healthcare industry. Lean in general is a well-known industrial approach which is focusing on creating value by eliminating waste through quality products and services (Hallam and Contreras, 2018; Shah and Ward, 2003). The Lean thinking in healthcare industry, emerging from the Japanese automotive industry, has been increasingly introduced in many hospitals over the last 20 years in order to improve productivity (Burgess and Radnor, 2013; Blouin-Delisle et al., 2018; de Souza, 2009; Heinbuch, 1995). According to the Wolfe (2001), there have been some important priorities such as responsiveness to the needs of patients, and on-time access to improve the healthcare system. Delays, for example, cause dissatisfaction with patients, with higher costs and potential unfavorable clinical effects (Green et al., 2007). Over the last years, much attention has been paid to the idea of lean healthcare, illustrated in the studies by the UK Institute for Innovation and Improvement and the US Institute for Healthcare Improvement (Waring and Bishop, 2010). In the UK and international health markets, the lean approach and its practices have been implemented and encouraged as a productivity reaction as public funding rises (McIntosh et al., 2014). Within the lean perspective, the inefficiencies, the non-value-added activities, and the errors should be eliminated.

In this context, the illumination in the OR needs to be managed and continually controlled. It also needs to be carefully supervised to ensure their optimum use, maximize efficiency and examined as a whole surgical procedure due to their high volume and the quality of treatment provided (Blouin-Delisle et al., 2018). Therefore, maintenance activities are the most important way to manage illumination. Maintenance is composed of preventive and breakdown maintenance. Preventive is divided into two categories as periodic and predictive in which both of them require measurement of illumination. However, rather than standard measurement activities, the values achieved at the end of measurement should be reliable and verified, and hence, the variability of the measurement process should be managed. 
Seagull (2012) stated that lighting within the OR is considered as crucial for the performance of the tasks and is a critical feature for an OR. Kaya et al. (2008), found that $60 \%$ of the surgery had problems with the manipulation of instruments owing to insufficient lightning in the OR. There are $34.9 \%$ occasionally difficulties faced through the usage of OR lights that cause dangerous hazards for both the OR team and patient (Matern and Koneczny, 2007). Based on the report of the World Health Organization (2012), the lights where heat protection filters were removed burned patients. Touching dirty fingers on a quartz-halogen lamp can also cause the bulb to fail in the early stages. Moreover, sometimes, disconnection or failure of fixture components can happen. Drury et al. (2004), indicate that more than $20 \%$ of the amount of light emitted by the current light has dark portions, which is the cause of errors during surgery. Matern and Koneczny (2007), presented that $41 \%$ of the surgeons experienced such a hazard caused by the OR lights for the surgery staff several times. The majority of the hazards reported were because of inadequate lighting in the OR, specifically resulting in dangerous consequences (Matern and Koneczny, 2007).

LED lamps, which have many advantages for both patients and doctors, are increasing day by day. There are different studies on the use of LED lamps in operation rooms. The subjects of these studies are the optical properties of the lamp (Ide et al., 2015), the reflection type lamp (Pan et al., 2016), the reliability of the lamps (Zheng et al., 2016), and the stability of the power supply. As can be seen, these studies are studies investigating the different properties of lamps. However, in none of these studies, an application has been made to measure and control the errors that occur with a lean perspective for the existing lamps. In terms of human health, zero tolerance is essential for the variations or errors in the measurement process. Thus, the main contribution of this study is that, to the best of our knowledge, this is the first study to determine the variability of measurement in the OR illumination measurement process. Based on the research objectives, the following two research questions were derived.

RQ1: What are the tools/techniques used to measure and check for errors caused by lamps available in ORs?

RQ2: How do we measure the errors caused by the existing lamps in the ORs by lean and six sigma approach?

In this study, the lean approach is integrated with Measurement System Analysis (MSA) and Gage Control methodology, a Six Sigma tool, to determine the measurement process variability. The underlying reason for proposing the integration of lean management and six sigma in healthcare organizations is to tackle medical patient safety and quality issues (Ahmed et al., 2019; Van den Heuvel et al., 2006). This can be regarded as the first study implementing the lean tool, MSA and Gage Control, for improving the efficiency of the healthcare industry.

The remainder of the paper is structured as follows: The review of the literature on lighting in ORs and lean approach in healthcare is presented in Section 2. Section 3 provides the proposed model. Six Sigma, MSA and Gage Control methodologies are introduced in Section 4. Section 5 defines the case and Section 6 provides the results of the application. In Section 7, the discussion and implication of the study are provided. Lastly, Section 8 presents the discussion of possible future research topics and conclusions. 
International Journal of Mathematical, Engineering and Management Sciences

Vol. 6, No. 3, 752-770, 2021

https://doi.org/10.33889/IJMEMS.2021.6.3.045

\section{Theoretical Background}

\subsection{Lighting}

The working environment and lighting are the most important factors for OR design from a surgeon's perspective (Katz, 2017; Quillin et al., 2019). Before the twentieth century, large windows provided sufficient daylight in ORs. Subsequently, daylight was replaced as the main source of lighting by high-power operating lamps (Albayrak et al., 2004).

OR lamps are designed to run for a long time without emitting too much heat. The International Electro-Technical Commission (IEC) defined the norms and main requirements for surgical lighting. Based on the document IEC 60601-2-41, surgical illumination should be good enough for deep, narrow or flat surfaces within a cavity.

Surgeons, anesthesiologists, and nurses need different types of light, such as conventional and LED. Conventional lamps, for instance, are incandescent gas-filled lamps which contains halogen as a gas with a pressure exceeding three atmospheres (atm). Although widely used, halogen lamps have many disadvantages. Usage times are much shorter than other lamp types. In particular, the open wound can cause overheating due to its large volume of light. Ultraviolet radiation produced by halogen lamps may even provoke skin cancer (Kamsah et al., 2018).

Unlike halogen lamps, using LED lamps has many advantages. LED lights involve modules that are very small semiconductors. They produce a narrow spectrum of light when stimulated by an electrical circuit. Sonmez et al. (2016) argued that, despite the price advantage of halogen lamps over LED lamps, the latter is preferred because they cause less environmental pollution and last longer.

Lighting can also be classified as a mounting configuration: overhead, floor stand or wall-mounted. For any type of surgery, overhead lights are the most commonly used source. The biggest advantage of using headlights is flexibility while limited mobility is one of the main drawbacks.

Sufficient light is needed for work-specific tasks because poor illumination can cause low productivity, eyestrain, headaches, reduced mental alertness, general weakness and low employee morale, and high human error rates. Especially in the health sector, the slightest mistake has a lot of impact on human life. In order to eliminate all these negativities, attention should be paid to the light used in the operation rooms. By comparing different devices and devices, errors due to light should be measured and necessary measures should be taken. This study reminds us of the importance of using MSA and Gage control.

\subsection{Lean Approach in Healthcare}

An increasing number of studies have analyzed application of lean philosophies within healthcare, generally presenting the advantages for patient care and resource efficiency (Jones and Filochowski, 2006; Joosten et al., 2009; Kaltenbrunner et al., 2019; Kim et al., 2006; Radnor and Boaden, 2008; Walley, 2003; Zidel, 2006). Also, studies show how lean practices vary within a systems-approach perspective while others implement lean tools and techniques.

A fair amount of research has investigated OR efficiency specifically. Harders et al. (2006) proposed a plan to minimize the tasks that are not related to surgery in the OR, such as performing simultaneous activities or complex nonclinical activities. Implementing this plan significantly decreased turnover time and anesthesia-related time. Cima et al. (2011), established a team for 
continuous process improvement that applied a value-stream map for surgical processes, each of which was examined for three issues: workforce, information and time. This significantly improved the operating timing schedules. Smith et al. (2013) categorized variation between operations as artificial (scheduled) or natural (unscheduled) to facilitate daily schedule and reduce artificial variations in the surgery day. Twelve-month data were analyzed by comparing with that of the previous year regarding prime-time use, overtime duration, variations in daily schedules, number of ORs and access for emergency cases. Significant improvements were seen in surgical volume and duration, prime-time use, overtime staffing, staff turnover, and operating margins. Attaallah et al. (2016) used electronic medical record analysis to identify errors in OR time utilization. They found that using data analysis, it is very easy to reveal OR time scheduling bias, errors and also utilization inefficiencies. Madni et al. (2017) identified the key performance factors and barriers in the OR process. They claimed that the three largest time components in an operation have been found as a surgeon, preparation, and turnover times. Souza et al. (2020) proposed that the effectiveness of ORs can be structured as the overall equipment effectiveness, to assess performance and reveal losses based on lean healthcare objectives.

\subsection{Lean Six Sigma Applications in Healthcare}

In the last decade, researchers have been researching different problems by combining Lean Approach and Six Sigma principles. The general purpose of both concepts is to reduce costs and improve processes by focusing on customer needs (Arthur, 2011). Considering its applications especially in the health sector, while focusing on improving the lean value stream, patient flow tries to minimize waste and make problems visible. For instance, Six Sigma focuses on accuracy and precision at certain stages of processes with statistical tools to enhance quality and tries to reduce performance variability (Antony and Kumar, 2012).

There are some studies on healthcare-related by integrated six sigma and lean approach techniques (DelliFraine et al., 2010; Gijo and Antony, 2014; Glasgow et al., 2010; Montella et al., 2017; Trakulsunti and Antony, 2018). Some of them conducted systematic literature reviews on empirical studies about Lean Six Sigma in healthcare. Two of them have focused on the registration process of the hospital undertaken in India (Bhat and Jnanesh, 2013; Bhat et al., 2014). Laureani et al. (2013) investigated five Lean Six-Sigma projects in a large hospital in Ireland. Trakulsunti and Antony (2018), implemented Lean and Six Sigma to minimize medication errors in four cases. Antony et al. (2019) explored Lean and Six Sigma in the Norwegian public healthcare to decrease medication errors. Ahmed et al. (2019) presented the Six Sigma applications within private hospitals in Malaysia. They measured Six Sigma initiatives in private hospitals based on descriptive statistics. Also, Hassanain (2017) assessed the applicability of the establishment of improving performance within the Saudi Arabia's Ministry of Health applying Lean Six Sigma principles.

MSA is one of the approaches for problem-solving and system improvements. It can be noted that continuously measuring, monitoring, and assessing performance is crucial for organizations. Effective data collection is a process that is necessary to be successful in measurement, monitoring, and assessment processes. Therefore, there is a need for a tool, the MSA and Gage Control, which enables the verification and validation of the data collection process (Sagnak and Kazancoglu, 2016). 
International Journal of Mathematical, Engineering and Management Sciences

Vol. 6, No. 3, 752-770, 2021

https://doi.org/10.33889/IJMEMS.2021.6.3.045

\section{Proposed Model}

An increasing number of researchers analyzed the application of lean philosophies in healthcare, generally presenting the advantages of patient care and resource efficiency (Jones and Filochowski, 2006; Joosten et al., 2009; Kim et al., 2006; Radnor and Boaden, 2008; Walley, 2003; Zidel, 2006). Another promising field of the lean approach in healthcare, specifically in the OR, is the lightning. The need for a lean approach for lightning is essential as cited in the literature.

In this context, lightning is an important issue to analyze to enhance the effectiveness and efficiency of the OR and to prevent errors. Therefore, the lean six sigma approach is proposed to control and manage the lightning via hiring MSA and Gage control, a six-sigma tool, for the measurement of illumination.

The illuminance plays a critical role in ORs for efficiency and effectiveness of the operations and aims to prevent faults that may be caused by poor illumination. Therefore, from a process management point of view, the illumination should be controlled in a continuous manner. Light systems play a major role in this aspect. There are various options for lighting systems such as xenon, halogen, and LED.

Especially, due to the comparatively longer mean life, and previously mentioned advantages, LED systems are studied in this study. The LED systems are composed of many LED bulbs. According to reliability studies, the mean life of a product can be calculated as (mean life $=1$ / failure rate); however, the actual life duration can be longer or shorter, because failure rate, and hence the mean life is based on probability distributions. Therefore, continuous control of illumination is necessary to sustain the proper illumination and to figure out the LED bulbs with relatively less performance to replace them.

According to the literature review, there are three types of OR problems: human factors, the physical environment, and surgeon-related factors. This study only considers lighting within the physical environment factor. Lighting selection, architecture, and illumination are the most important physical issues in ORs. More specifically, preventive maintenance is very important for managing and controlling OR illumination. Within lighting maintenance, accurate measurement is critical because there is a need for a zero-tolerance approach against measurement variations or errors due to the implications for patient health. The lean perspective highlights the causes of inefficiencies, non-value-added activities, and errors. This approach can thus be applied to determine measurement variability in OR illumination measurement. Figure 1 outlines the proposed model to identify variability in the measurement process. The proposed model is based on a combination of the Six Sigma tool, MSA and Gage Control methods. 


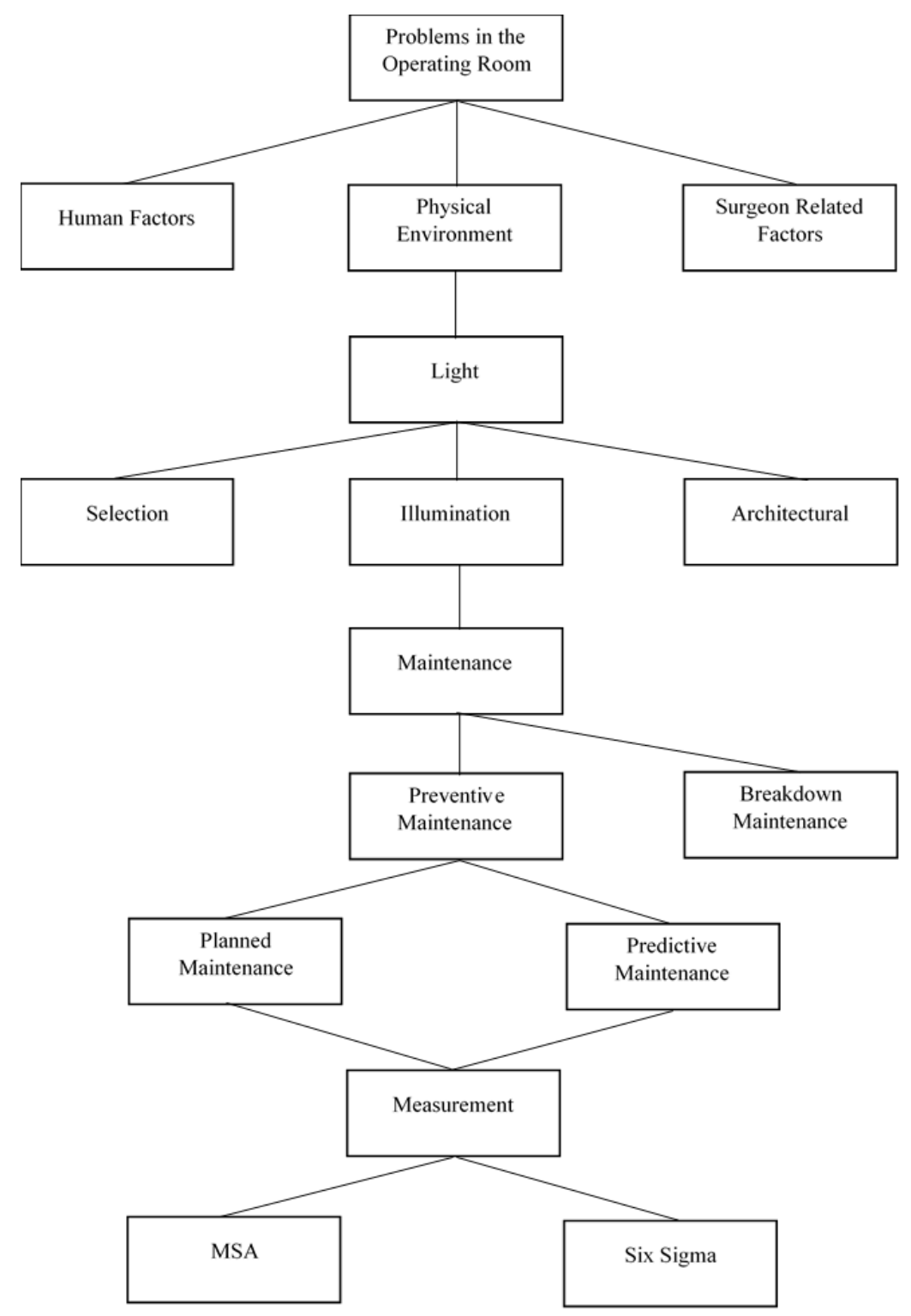

Figure 1. Proposed model.

In the next section, methodology, MSA and Gage control was discussed.

\section{Methodology: MSA \& Gage Control}

MSA is an analytical tool composed of principles for evaluating the measurement system. The main aim of MSA is to determine the effects of different variations in measurement process; thus, statistical approaches are employed to highlight the reproducibility and repeatability of the measurement (Dalalah and Diabat, 2015). Gage Control was decided to be used because of its ability for validation and verification of the data collection process. The performance of the processes can be measured, and monitored through Gage Control methodology in a continuous manner (Sagnak and Kazancoglu, 2016). 
Measurements are necessary for ensuring effective analyses and realistic decisions in quality management systems (Pyzdek and Keller, 2003). Measurement data present if processes take place as desired while monitoring the statistical control limits. If a process is within these limits then it is in control and can continue under the present configuration; if not, corrective actions should be taken.

Total variation comprises two types of variations; processes and measurements. Therefore, measurement variations should be revealed and differentiated from process variations (Montgomery, 2007). The relevant formulation is as follows (Besterfield, 2004; Hajipour et al., 2013; Kuo and Huang, 2013).

Let $n$ denotes the number of parts, $r$ the number of trials, whereas $k$ the number of appraisers. $\overline{\mathrm{X}}$ is used to represent the average of the measurements and $\mathrm{R}$ stands for the range.

Step 1: Find the part averages and the part ranges for each part and each appraiser with (1), and (2), respectively.

$\overline{\mathrm{X}}=\frac{\sum_{\mathrm{i}=1}^{\mathrm{r}} \mathrm{X}_{\mathrm{i}}}{\mathrm{r}}$

$\mathrm{R}=\mathrm{X}_{\max }-\mathrm{X}_{\min }$.

Step 2: Find the average and range for individual measurements for each appraiser with formulas (3), and (4), respectively.

$$
\begin{aligned}
& \overline{\bar{X}}_{\text {app }}=\frac{\sum_{\mathrm{i}=1}^{\mathrm{n}} \overline{\mathrm{X}}_{\mathrm{i}}}{\mathrm{n}}, \\
& \overline{\mathrm{R}}_{\mathrm{app}}=\frac{\sum_{\mathrm{i}=1}^{\mathrm{n}} \mathrm{R}_{\mathrm{i}}}{\mathrm{n}} .
\end{aligned}
$$

Step 3: Find the overall part average and part range for each part with (5), and (6), respectively.

$$
\begin{aligned}
& \overline{\mathrm{X}}_{\mathrm{p}}=\frac{\sum_{\mathrm{i}=1}^{\mathrm{k}} \overline{\mathrm{x}}_{\mathrm{i}}}{\mathrm{k}} \\
& \mathrm{R}_{\mathrm{p}}=\overline{\overline{\mathrm{X}}}_{\mathrm{p}, \max }-\overline{\mathrm{X}}_{\mathrm{p}, \min } .
\end{aligned}
$$

Step 4: Find the appraisers' average of range with the formula (7).

$\overline{\overline{\mathrm{R}}}_{\mathrm{app}}=\frac{\sum_{\mathrm{i}=1}^{\mathrm{k}} \overline{\mathrm{R}}_{\mathrm{app}, \mathrm{i}}}{\mathrm{k}}$

Step 5: Find the difference among the maximum and the minimum of average for individual measurements with the formula (8).

$\overline{\bar{X}}_{\text {diff }}=\overline{\bar{X}}_{\mathrm{app}, \max }-\overline{\bar{X}}_{\mathrm{app}, \min }$ 
Step 6: Find the lower and upper control limits (the values of $\mathrm{D}_{3}$ and $\mathrm{D}_{4}$ can be found in Appendix A) with formulas (9), and (10), respectively.

$$
\begin{aligned}
& \mathrm{LCL}_{\mathrm{R}}=\mathrm{D}_{3} \times \overline{\overline{\mathrm{R}}}_{\mathrm{app}} \\
& \mathrm{UCL}_{\mathrm{R}}=\mathrm{D}_{4} \times \overline{\overline{\mathrm{R}}}_{\mathrm{app}} .
\end{aligned}
$$

Step 7: Find variations for equipment (repeatability), appraiser (reproducibility), measurement system variation, part variation, and total variation with formulas (11-15), respectively.

$$
\begin{aligned}
& \text { Equipment Variation: } \mathrm{EV}=\mathrm{r} \times \overline{\overline{\mathrm{R}}}_{\mathrm{app}} \\
& \text { Appraiser Variation: } \mathrm{AV}=\sqrt{\left(\mathrm{k} \times \overline{\mathrm{X}}_{\mathrm{diff}}\right)^{2}-\left(\mathrm{EV}^{2} / \mathrm{n} \times \mathrm{r}\right)} \\
& \text { Measurement System Variation: } \mathrm{R} \& \mathrm{R}=\sqrt{\mathrm{EV}^{2}+\mathrm{AV}^{2}} \\
& \text { Part Variation: } \mathrm{PV}=\mathrm{j} \times \mathrm{R}_{\mathrm{p}} \\
& \text { Total Variation: } \mathrm{TV}=\sqrt{\mathrm{R} \& \mathrm{R}^{2}+\mathrm{PV}^{2}}
\end{aligned}
$$

Step 8: Find the percentages by dividing each variation value to the total variation value.

$$
\begin{aligned}
& \% \mathrm{EV}=100 \times(\mathrm{EV} / \mathrm{TV}) \\
& \% \mathrm{AV}=100 \times(\mathrm{AV} / \mathrm{TV}) \\
& \% \mathrm{R} \& \mathrm{R}=100 \times(\mathrm{R} \& \mathrm{R} / \mathrm{TV}) \\
& \% \mathrm{PV}=100 \times(\mathrm{PV} / \mathrm{TV})
\end{aligned}
$$

If measurement system variation ( $\% \mathrm{R} \& \mathrm{R})$ is smaller than $10 \%$, then the gage system is called as satisfactory. If measurement system variation ( $\% R \& R)$ is smaller than $30 \%$, the gage system may be called as acceptable. If it is larger than $30 \%$, the gage system is unsatisfactory.

\section{Case Study}

The application has been conducted in a private hospital located in Izmir. The hospital, was established on a total area of 46,000 square meters, has a total of 301 patient beds, 10 of which are disabled beds, and 29 internal-surgical intensive care beds, 7 intensive care beds, 7 coronary intensive care beds, 35 neonatal intensive care bed serves with a total of 88 intensive care beds. In the hospital, which has 7 general ORs, 2 cardiovascular surgery ORs, 4 gynecology and 1 ophthalmology intervention room, the total emergency unit bed capacity is 14 beds. The hospital, which includes all departments that should be in a full-fledged hospital, is also the largest private hospital in the Aegean Region, Turkey. Surgical operations can be performed in all branches in the ORs with 24/7 service with its experienced staff. Hygienic conditions are applied meticulously at the highest level in ORs.

The surgical lights of three randomly selected ORs are measured by a lux meter. In this application, central illuminance, which is the illuminance at $1 \mathrm{~m}$ distance from the light-emitting surface in the 
light field center is studied. The LED lights in the application are the professional led light system for major surgery containing 84 led bulbs.

Three appraisers are used, each having three measures in each one of the ORs. Each appraiser performed three trial tests upon three parts, therefore a total of nine measurements for each. Data were collected from three randomly selected parts. Three appraisers are also selected randomly, and called as appraiser A, B, and C, respectively. Afterward, the gage system was conducted randomly three times by each appraiser.

The lux meter used is a LED light meter to record and save the measurements. The measurement rate of the light meter is 1.5 timer per second, nominal. Also, the dimensions of the light meter are $188 \mathrm{~mm}$ height, $64.5 \mathrm{~mm}$ width and $24.5 \mathrm{~mm}$ depth with $160 \mathrm{gr}$ weight. The data of lux measurements can be seen in Table 1 .

Table 1. Lux measurements by three appraisers for three lighting sources.

\begin{tabular}{|l|c|c|c|}
\hline & \multicolumn{3}{|c|}{ Part Numbers } \\
\hline & $\mathbf{1}$ & $\mathbf{2}$ & $\mathbf{3}$ \\
\hline Appraiser A & & 154790 & 154910 \\
\hline Trial 1 & 154850 & 154800 & 154900 \\
\hline Trial 2 & 154850 & 154800 & 154900 \\
\hline Trial 3 & 154850 & & 154850 \\
\hline Appraiser B & & 154820 & 154860 \\
\hline Trial 1 & 154880 & 154820 & 154860 \\
\hline Trial 2 & 154890 & 154820 & 154860 \\
\hline Trial 3 & 154880 & & 154870 \\
\hline Appraiser C & & 154810 & 154860 \\
\hline Trial 1 & 154870 & 154820 & 154810 \\
\hline Trial 2 & 154870 & & \\
\hline Trial 3 & 154870 & & \\
\hline
\end{tabular}

\section{Results}

The data given in Table 1 were analyzed using gage control methodology. Table 2 shows the relevant data for parts for each trial, for each appraiser.

The difference between the maximum and minimum of average for individual measurements was calculated as follows:

$$
\begin{aligned}
& \overline{\bar{X}}_{\text {diff }}=154853.33-154848.89=4.44, \\
& \overline{\bar{R}}_{a p p}=\left(\bar{R}_{a}+\bar{R}_{b}+\bar{R}_{c}\right) \div 3=(6.67+6.67+6.67) \div 3=6.67, \\
& U C L_{R}=D_{4} \times \overline{\bar{R}}_{a p p}=2.574 \times 6.67=17.16, \\
& L C L_{R}=D_{3} \times \overline{\bar{R}}_{a p p}=0 \times 466.67=0 .
\end{aligned}
$$

Lower $\left(\mathrm{LCL}_{\mathrm{R}}\right)$ and upper $\left(\mathrm{UCL}_{\mathrm{R}}\right)$ control limits for the $R$ chart were calculated. If any measurement was found located outside of the control limits, it should be eliminated, and the revised control limits should be calculated. Figure 2 shows that the observations located among the upper and lower control limits, which indicates that the system is in control. For all three appraisers, the two of the part ranges were above average. 
International Journal of Mathematical, Engineering and Management Sciences

Vol. 6, No. 3, 752-770, 2021

https://doi.org/10.33889/IJMEMS.2021.6.3.045

Table 2. Results of application of gage control methodology.

\begin{tabular}{|l|c|c|c|c|c|}
\hline & \multicolumn{3}{|c|}{ Part Numbers } & Appraiser & Appraiser \\
\hline & $\mathbf{1}$ & $\mathbf{2}$ & $\mathbf{3}$ & $\bar{X}$ & $\overline{\boldsymbol{R}}$ \\
\hline Appraiser A & & & & & \\
\hline Trial 1 & 154850 & 154790 & 154910 & & \\
\hline Trial 2 & 154850 & 154800 & 154900 & & \\
\hline Trial 3 & 154850 & 154800 & 154900 & & \\
\hline $\bar{X}$ & 154850 & 154796.67 & 154903.33 & 154850 & \\
\hline$R$ & 0 & 10 & 10 & & \\
\hline Appraiser B & & & & & \\
\hline Trial 1 & 154880 & 154820 & 154850 & & \\
\hline Trial 2 & 154890 & 154820 & 154860 & & \\
\hline Trial 3 & 154880 & 154820 & 154860 & & \\
\hline $\bar{X}$ & 154883.33 & 154820 & 154856.67 & 154853.33 & \\
\hline$R$ & 10 & 0 & 10 & & \\
\hline Appraiser C & & & & & \\
\hline Trial 1 & 154870 & 154810 & 154860 & & \\
\hline Trial 2 & 154870 & 154820 & 154870 & & \\
\hline Trial 3 & 154870 & 154810 & 154860 & & \\
\hline $\bar{X}$ & 154870 & 154813.33 & 154863.33 & 154848.89 & \\
\hline$R$ & 0 & 10 & 10 & & \\
\hline $\bar{R}$ & 154867.78 & 154810 & 154874.44 & Part Range & 6.67 \\
\hline Part $X$ & & & & \\
\hline
\end{tabular}

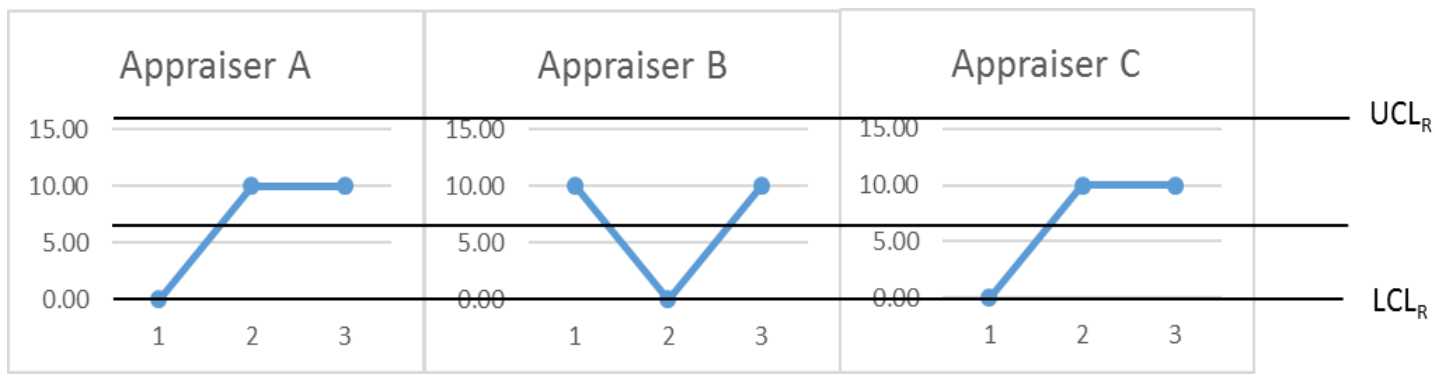

Figure 2. Appraiser range graph.

Repeatability (Equipment Variation): As mentioned before, repeatability identifies variation caused by differences in measurements of the same part by the same appraiser.

$E V=r \times \overline{\bar{R}}_{a p p}=3.05 \times 6.67=20.34$,

$\mathrm{r}=3.05$ for 3 trials.

Reproducibility (Appraiser Variation): As mentioned before, reproducibility identifies variation caused by differences in measurements of the same part by the different appraisers.

$\mathrm{k}=2.70$ for 3 appraisers,

$$
A V=\sqrt{\left(k \times \overline{\bar{X}}_{\text {diff }}\right)^{2}-\left(E V^{2} / n \times r\right)}=\sqrt{(2.70 \times 4.44)^{2}-\left(20.34^{2} / 3 \times 3\right)}=9.90
$$


International Journal of Mathematical, Engineering and Management Sciences

Vol. 6, No. 3, 752-770, 2021

https://doi.org/10.33889/IJMEMS.2021.6.3.045

Repeatability and Reproducibility:

$R \& R=\sqrt{E V^{2}+A V^{2}}=\sqrt{20.34^{2}+9.9^{2}}=22.62$.

Part Variation: Total variation caused by differences in measurements of parts sampled in a fixed period. Table 3 shows the values for $j$.

Table 3. Dependent on number of parts (j).

\begin{tabular}{|c|c|c|c|c|c|c|c|c|c|c|}
\hline \multicolumn{9}{|c|}{ Part Number } \\
\hline & 1 & 2 & 3 & 4 & 5 & 6 & 7 & 8 & 9 & 10 \\
\hline $\mathrm{j}=$ & & 3.65 & 2.7 & 2.3 & 2.08 & 1.93 & 1.82 & 1.74 & 1.67 & 1.62 \\
\hline
\end{tabular}

$P V=j \times R_{p}=2.7 \times 64.44=174$.

Total Variation:

$T V=\sqrt{R \& R^{2}+P V^{2}}=\sqrt{22.62^{2}+174^{2}}=175.46$.

The percentage variation concerning the total variation was determined as follows:

$$
\begin{aligned}
& \% E V=100 \times(E V / T V)=100 \times(20.34 / 175.46)=11.59 \%, \\
& \% A V=100 \times(A V / T V)=100 \times(9.90 / 175.46)=5.64 \%, \\
& \% R \& R=100 \times(R \& R / T V)=100 \times(22.62 / 175.46)=12.89 \%, \\
& \% P V=100 \times(P V / T V)=100 \times(174 / 175.46)=99.16 \% .
\end{aligned}
$$

According to these calculations, \%R\&R was $12.89 \%$. Given the $\mathrm{R} \& \mathrm{R}$ limits defined earlier, it can be said that there was a problem in the gage control procedure.

EV\% (11.59\%) was also higher than AV\% (5.64\%), indicating that the determining factor was the measuring equipment. Therefore, the LED lighting analyzers need to be recalibrated or the LED light meter needs to be changed.

According to the analysis and the suggestions of this study, hospital management decided to recalibrate their measurement equipment. The percentage of variation concerning total variation was calculated as follows:

$$
\begin{aligned}
& \% E V=100 \times(E V / T V)=100 \times(10.17 / 216.73)=4.69 \%, \\
& \% R \& R=100 \times(R \& R / T V)=100 \times(17.80 / 216.73)=8.21 \% .
\end{aligned}
$$


International Journal of Mathematical, Engineering and Management Sciences

Vol. 6, No. 3, 752-770, 2021

https://doi.org/10.33889/IJMEMS.2021.6.3.045

The $\% \mathrm{R} \& \mathrm{R}$ was found as $8.21 \%$. Thus, recalibration reduced $\% \mathrm{R} \& \mathrm{R}$ from $12.89 \%$ to $8.21 \%$. Due to recalibration, \%EV decreased from $11.59 \%$ to $4.69 \%$, which implies that recalibration helped reduce variability. Given the R\&R limits defined earlier, it can be said that gage control became satisfactory after recalibration.

In short, the initial MSA results indicated that the measurement system was not satisfactory and that the measurement equipment needed to be recalibrated. The follow-up results showed that the measurement system became satisfactory following the equipment recalibration approved by hospital management.

In healthcare whenever there is a process involving measurement activity, it is subject to the risk of measurement error. Therefore, to improve the quality in healthcare the measurement analysis can be taken into consideration. The people, devices, or the processes may vary among the healthcare; but the concepts and the methodology shall be taken as a reference to prevent measurement errors.

\section{Discussion \& Implications}

Lean management and six sigma tools and techniques promise important outcomes and managerial implications for healthcare management. The wastes and inefficiencies can be eliminated with the lean philosophy. This will contribute both to the increase in quality and elimination of errors. The occurrence of errors may cause severe problems to patients and healthcare staff. The errors made in healthcare operations may even cause death or injuries. Thus, elimination of errors is a potential field for lean healthcare studies.

Therefore, several implications can be asserted for managers in the healthcare industry. Lean management should be implemented throughout the organization with a holistic approach. The reasons for errors and inefficiencies should be figured out. Afterward, lean six sigma should be incorporated with each of the processes within the facility (Sagnak and Kazancoglu, 2016).

The lean six sigma activities must be supported by the top management to allocate the necessary resources. The necessary training activities should be conducted for the personnel. There is a need for interdisciplinary participation of personnel to meet the requirements of lean six sigma activities. Therefore, the matrix organization model can be used to constitute the lean six sigma based on interdisciplinary teams.

The ORs, which is emphasized in this study, is an important location to constitute lean six sigma within healthcare facilities. The possibility of errors within the ORs may cause severe consequences. The tools and techniques of lean six sigma can be applied to a wide range of implementations that needs to be controlled such as illumination, air conditioning, humidity, etc. Especially illumination is a promising concern to be addressed due to its substantial criticality in preventing fatal errors during surgeries.

This study implies several points for policymakers, too (Hallam and Contreras, 2018). The policymakers may emphasize the importance of lean management and six sigma for the healthcare industry. The government can state the rules and regulations to turn to lean six sigma into a compulsory action throughout healthcare facilities. The efforts towards the elimination and prevention of errors within healthcare operations should be supported, encouraged, and controlled by the government. 
International Journal of Mathematical, Engineering and Management Sciences

Vol. 6, No. 3, 752-770, 2021

https://doi.org/10.33889/IJMEMS.2021.6.3.045

The government and local authorities may also focus on disseminating the lean six sigma tools and techniques. Thus, educational programs can be established and subsidized. Distance learning can be another option to spread out the necessary knowledge on lean six sigma. The policymakers may ask and require companies to hire certified personnel on lean six sigma.

\section{Conclusions}

In healthcare systems, there is a direct relationship between surgery performance and patient health. Therefore, it is necessary to adopt a multidisciplinary approach to improve both the quality and performance of surgery. The physical workplace is a key element for increasing surgeons' job performance, in particular the OR itself.

As well as the ergonomic characteristics of equipment and devices, OR lighting is critical for surgeons, because there is a fact that almost $80 \%$ of external stimuli affect eyes. As Seagull (2012) noted, lighting within the OR is accepted as crucial for the performance of the tasks.

LED lamps, which have many advantages for both patients and doctors, are increasing day by day. Although there have been various studies on the use of LED lamps, none has been made to measure and control the errors or variations that occur with a lean perspective for the existing lamps. This paper investigated the integration of a lean six sigma approach in measuring lighting efficiency. Accurate and precise measurement is important because there is a need for a zero-tolerance approach for variations or errors due to the implications for patient health.

The major contribution of this study is that, to the best of our knowledge, this is the first study to determine the variability of measurement in OR illumination measurement process and combine Six Sigma with a lean approach to healthcare management, and its proposal of MSA and Gage Control to fulfill the need for measurement in maintaining OR lighting. This can be regarded as the first study implementing the all mentioned technique, for improving the efficiency of the healthcare industry.

The study's initial results showed that the measurement system was not satisfactory, thereby demonstrating a need for recalibrating the measurement equipment. Hospital management approved this recalibration and the follow-up results showed that recalibration improved the measurement system to a satisfactory level. In addition, regarding the study's practical implications, hospital management accepted to apply MSA and gage Control as a lean six sigma tool and ordered that the suggested methodology be used for various medical devices within hospital departments.

One of the limitations of this study is that the application is conducted in a single hospital. Besides, the fact that possible integration or synchronous use of multiple types of equipment may affect the results of the proposed methodology. Meanwhile, the macro conditions that cannot be controlled, such as environmental or climatic conditions, may cause measurement errors during the measurement process can be listed as another limitation of the study.

Several implications can be asserted in the healthcare industry. From a managerial perspective, there may be a need for a holistic approach to applying lean principles for healthcare in order to figure out the inefficiencies. For policymakers, there may be a need for some rules and regulations to use lean tools to eliminate inefficiencies in healthcare facilities. 
International Journal of Mathematical, Engineering and Management Sciences

Vol. 6, No. 3, 752-770, 2021

https://doi.org/10.33889/IJMEMS.2021.6.3.045

Future studies could focus on to integrate a lean approach with six sigma in healthcare, various tools, such as the design of experiments, process capability analysis, and statistical process control charts could be used. In addition to that, from practical implication point of view, the hospital management has decided to apply MSA and gage control, as a lean six sigma tool, and declared the suggested methodology as a procedure to be followed in different medical devices that are used within the departments of the hospital.

\section{Conflict of Interest}

The authors confirm that is no conflict of interest to declare for this publication.

Acknowledgements

Authors express their sincere thanks to the private hospital fort the case study.

\section{References}

Aganovic, A., Cao, G., Stenstad, L.I., \& Skogås, J.G. (2017). Impact of surgical lights on the velocity distribution and airborne contamination level in an operating room with laminar airflow system. Building and Environment, 126, 42-53.

Ahmed, S., Abd Manaf, N.H., \& Islam, R. (2019). Effects of Six Sigma initiatives in Malaysian private hospitals. International Journal of Lean Six Sigma, 10(1), 44-57.

Albayrak, A., Kazemier, G., Meijer, D.W., \& Bonjer, H.J. (2004). Current state of ergonomics of operating rooms of Dutch hospitals in the endoscopic era. Minimally Invasive Therapy \& Allied Technologies, 13(3), 156-160.

Antony, J., \& Kumar, M. (2012). Lean and Six Sigma methodologies in NHS Scotland: an empirical study and directions for future research. Quality Innovation Prosperity, 16(2), 19-34.

Antony, J., Forthun, S.C., Trakulsunti, Y., Farrington, T., McFarlane, J., Brennan, A., \& Dempsey, M. (2019). An exploratory study into the use of lean six sigma to reduce medication errors in the Norwegian public healthcare context. Leadership in Health Services, 32(4), 509-524.

Arthur, J. (2011). Lean Six Sigma for hospitals: Simple steps to fast, affordable, and flawless healthcare. Tata McGraw-Hill Education, New York.

Attaallah, A.F., Elzamzamy, O.M., Phelps, A.L., Ranganthan, P., \& Vallejo, M.C. (2016). Increasing operating room efficiency through electronic medical record analysis. Journal of Perioperative Practice, 26(5), 106-113.

Azouz, S., Boyll, P., Swanson, M., Castel, N., Maffi, T., \& Rebecca, A.M. (2019). Managing barriers to recycling in the operating room. The American Journal of Surgery, 217(4), 634-638.

Besterfield, D.H. (2004). Quality Control. Pearson.

Bhat, S., \& Jnanesh, N.A. (2013). Enhancing performance of the health information department of a hospital using lean Six Sigma methodology. International Journal of Six Sigma and Competitive Advantage, 8(1), 34-50.

Bhat, S., Gijo, E.V., \& Jnanesh, N.A. (2014). Application of lean six sigma methodology in the registration process of a hospital. International Journal of Productivity and Performance Management, 63(5), 613643. 
International Journal of Mathematical, Engineering and Management Sciences

Vol. 6, No. 3, 752-770, 2021

https://doi.org/10.33889/IJMEMS.2021.6.3.045

Blouin-Delisle, C.H., Drolet, R., Gagnon, S., Turcotte, S., Boutet, S., Coulombe, M., \& Daneau, E. (2018). Improving flow in the OR: how lean process studies can lead to shorter stays in the recovery ward. International Journal of Health Care Quality Assurance, 31(2), 150-161.

Brackett, T., Comer, L., \& Whichello, R. (2013). Do lean practices lead to more time at the bedside? Journal for Healthcare Quality, 35(2), 7-14.

Budhiraja G.D. (2010). The Natural Way of Healthy Aging. Diamond Pocket Books Ltd.

Burgess, N., \& Radnor, Z. (2013). Evaluating lean in healthcare. International Journal of Health Care Quality Assurance, 26(3), 220-235.

Cardoen, B., Demeulemeester, E., \& Beliën, J. (2010). Operating room planning and scheduling: a literature review. European Journal of Operational Research, 201(3), 921-932.

Cima, R.R., Brown, M.J., Hebl, J.R., Moore, R., Rogers, J.C., Kollengode, A., Amstutz, G.J., Weisbrod, C.A., Narr, B.J., Deschamps, C., \& Team, S.P.I. (2011). Use of lean and six sigma methodology to improve operating room efficiency in a high-volume tertiary-care academic medical center. Journal of the American College of Surgeons, 213(1), 83-92.

Cookson, D., Read, C., Mukherjee, P., \& Cooke, M. (2011). Improving the quality of emergency department care by removing waste using lean value stream mapping. The International Journal of Clinical Leadership, 17(1), 25-30.

D’Andreamatteo, A., Ianni, L., Lega, F., \& Sargiacomo, M. (2015). Lean in healthcare: a comprehensive review. Health Policy, 119(9), 1197-1209.

Dalalah, D., \& Diabat, A. (2015). Repeatability and reproducibility in med labs: a procedure to measurement system analysis. IET Science, Measurement \& Technology, 9(7), 826-835.

De Souza, L.B. (2009). Trends and approaches in lean healthcare. Leadership in Health Services, 22(2), 121139.

Deblois, S., \& Lepanto, L. (2016). Lean and Six Sigma in acute care: a systematic review of reviews. International Journal of Health Care Quality Assurance, 29(2), 192-208.

DelliFraine, J.L., Langabeer, J.R., \& Nembhard, I.M. (2010). Assessing the evidence of six sigma and lean in the health care industry. Quality Management in Healthcare, 19(3), 211-225.

Drury, N.E., Pollard, R., \& Dyer, J.P. (2004). Minimally invasive surgery: only as good as the picture. Annals of the Royal College of Surgeons of England, 86(1), 40-41.

Fairley, M., Scheinker, D., \& Brandeau, M.L. (2019). Improving the efficiency of the operating room environment with an optimization and machine learning model. Health Care Management Science, 22(4), 756-767.

Fong, A.J., Smith, M., \& Langerman, A. (2016). Efficiency improvement in the operating room. Journal of Surgical Research, 204(2), 371-383.

Gijo, E.V., \& Antony, J. (2014). Reducing patient waiting time in outpatient department using lean six sigma methodology. Quality and Reliability Engineering International, 30(8), 1481-1491.

Glasgow, J.M., Scott-Caziewell, J.R., \& Kaboli, P.J. (2010). Guiding inpatient quality improvement: a systematic review of lean and six sigma. The Joint Commission Journal on Quality and Patient Safety, 36(12), 533-540.

Green, L.V., Savin, S., \& Murray, M. (2007). Providing timely access to care: what is the right patient panel size? The Joint Commission Journal on Quality and Patient Safety, 33(4), 211-218.

Griefahn, B. (1992), Arbeitsmedizin. In: Schlick, C., Luczak, H., \& Bruder, R. (eds) Arbeitsperson. Enke, Stuttgart. 
International Journal of Mathematical, Engineering and Management Sciences

Vol. 6, No. 3, 752-770, 2021

https://doi.org/10.33889/IJMEMS.2021.6.3.045

Hajipour, V., Kazemi, A., \& Mousavi, S.M. (2013). A fuzzy expert system to increase accuracy and precision in measurement system analysis. Measurement, 46(8), 2770-2780.

Hallam, C.R., \& Contreras, C. (2018). Lean healthcare: scale, scope and sustainability. International Journal of Health Care Quality Assurance, 31(7), 684-696.

Harders, M., Malangoni, M.A., Weight, S., \& Sidhu, T. (2006). Improving operating room efficiency through process redesign. Surgery, 140(4), 509-516.

Hassanain, M. (2017). An overview of the performance improvement initiatives by the ministry of health in the kingdom of Saudi Arabia. INQUIRY: The Journal of Health Care Organization, Provision, and Financing, 54, 1-6.

Heinbuch, S.E. (1995). A case of successful technology transfers to health care: total quality materials management and just-in-time. Journal of Management in Medicine, 9(2), 48-56.

Ibrahim, A.M., Dimick, J.B., \& Joseph, A. (2017). Building a better operating room: views from surgery and architecture. Annals of Surgery, 265(1), 34-36.

Ide, T., Kinugawa, Y., Nobae, Y., Suzuki, T., Tanaka, Y., Toda, I., \& Tsubota, K. (2015). LED light characteristics for surgical shadow less lamps and surgical loupes. Plastic and Reconstructive Surgery Global Open, 3(11), Article number e562.

Jones, D., \& Filochowski, J. (2006). Lean healthcare: think yourself thin. The Health Service Journal, 116(6000), 6-7.

Joosten, T., Bongers, I., \& Janssen, R. (2009). The application of lean to healthcare: issues and observations. International Journal for Quality in Health Care, 21(5), 341-347.

Kaltenbrunner, M., Mathiassen, S.E., Bengtsson, L., \& Engström, M. (2019). Lean maturity and quality in primary care. Journal of Health Organization and Management, 33(2), 141-154.

Kamsah, N., Kamar, H.M., Alhamid, M.I., \& Yinn, W.K. (2018). Impacts of temperature on airborne particles in a hospital operating room. Journal of Advanced Research in Fluid Mechanics and Thermal Sciences, 44(1), 12-23.

Katz, J.D. (2017). Control of the environment in the operating room. Anesthesia \& Analgesia, 125(4), 12141218.

Kaya, O.I., Moran, M., Ozkardes, A.B., Taskin, E.Y., Seker, G.E., \& Ozmen, M.M. (2008). Ergonomic problems encountered by the surgical team during video endoscopic surgery. Surgical Laparoscopy, Endoscopy \& Percutaneous Techniques, 18(1), 40-44.

Kim, C.S., Spahlinger, D.A., Kin, J.M., \& Billi, J.E. (2006). Lean health care: what can hospitals learn from a world-class automaker? Journal of Hospital Medicine: an official publication of the Society of Hospital Medicine, 1(3), 191-199.

Krupka, D.C., \& Sandberg, W.S. (2006). Operating room design and its impact on operating room economics. Current Opinion in Anaesthesiology, 19(2), 185-191.

Kuo, C.C, \& Huang, P.J. (2013) Repeatability and reproducibility study of thin film optical measurement system. Optik-International Journal for Light and Electron Optics, 124(18), 3489-3493.

Laureani, A., Brady, M., \& Antony, J. (2013). Applications of lean six sigma in an Irish hospital. Leadership in Health Services, 26(4), 322-337.

Macario, A., Vitez, T.S., Dunn, B., \& McDonald, T. (1995). Where are the costs in perioperative care? analysis of hospital costs and charges for inpatient surgical care. The Journal of the American Society of Anesthesiologists, 83(6), 1138-1144. 
International Journal of Mathematical, Engineering and Management Sciences

Vol. 6, No. 3, 752-770, 2021

https://doi.org/10.33889/IJMEMS.2021.6.3.045

Madni, T.D., Imran, J.B., Clark, A.T., Arnoldo, B.A., Phelan, H.A., \& Wolf, S.E. (2017). Analysis of operating room efficiency in a burn center. Journal of Burn Care \& Research, 39(1), 89-93.

Matern, U., \& Koneczny, S. (2007). Safety, hazards and ergonomics in the operating room. Surgical Endoscopy, 21(11), 1965-1969.

McIntosh, B., Sheppy, B., \& Cohen, I. (2014). Illusion or delusion-lean management in the health sector. International Journal of Health Care Quality Assurance, 27(6), 482-492.

Montella, E., Di Cicco, M.V., Ferraro, A., Centobelli, P., Raiola, E., Triassi, M., \& Improta, G. (2017). The application of lean six sigma methodology to reduce the risk of healthcare-associated infections in surgery departments. Journal of Evaluation in Clinical Practice, 23(3), 530-539.

Montgomery, D.C. (2007). Introduction to statistical quality control. John Wiley \& Sons, New York.

Pan, C.T., Chen, Y.C., Yang, T.L., Lin, P.H., Lin, P.H., \& Huang, J.C. (2016). Study of reflection-typed LED surgical shadow less lamp with thin film Ag-based metallic glass. Optik, 127(4), 2193-2196.

Pyzdek, T., \& Keller, P.A. (2003). Quality Engineering Handbook. CRC Press.

Quillin, R.C., Cortez, A.R., Garcia, M.A., Winer, L.K., Kassam, A.F., Kuethe, J.W., \& Pritts, T.A. (2019). Gas off, room lights on: shedding light on the surgical resident's experience in open and laparoscopic surgery. Surgery, 166(4), 460-468.

Radnor, Z., \& Boaden, R. (2008). Lean in the public services: panacea or paradox? Public Money and Management, 28(1), 3-7.

Refaie, R., Rushton, P., McGovern, P., Thompson, D., Serrano-Pedraza, I., Rankin, K.S., \& Reed, M. (2017). The effect of operating lights on laminar flow: an experimental study using neutrally buoyant helium bubbles. The Bone \& Joint Journal, 99(8), 1061-1066.

Sagnak, M., \& Kazancoglu, Y. (2016). Integration of green lean approach with six sigma: an application for flue gas emissions. Journal of Cleaner Production, 127, 112-118.

Seagull, F.J. (2012). Disparities between industrial and surgical ergonomics. Work, 41(1), 4669-4672.

Shah, R., \& Ward, P.T. (2003). Lean manufacturing: context, practice bundles, and performance. Journal of Operations Management, 21(2), 129-149.

Smith, C.D., Spackman, T., Brommer, K., Stewart, M.W., Vizzini, M., Frye, J., \& Rupp, W.C. (2013). Reengineering the operating room using variability methodology to improve health care value. Journal of the American College of Surgeons, 216(4), 559-568.

Sonmez, A., Unlu, B., Ozgen, C., Bestel, E., Celik, H.H, Kara, H.H., Kunduraci, I.F., Yaran, O., Akkustur, Z., \& Isler, Y. (2016). Led teknolojilerinin ameliyathane lambalarında kullanımı. retrieved from: http://www.emo.org.tr/ekler/34ef4d1f815fba3_ek.pdf

Souza, T.A., Vaccaro, G.L.R., \& Lima, R.M. (2020). Operating room effectiveness: a lean health-care performance indicator. International Journal of Lean Six Sigma, 11(5), 987-1002.

Stahl, J.E., Sandberg, W.S., Daily, B., Wiklund, R., Egan, M.T., Goldman, J.M., Isaacson, K.B., Gazelle, S., \& Rattner, D.W. (2006). Reorganizing patient care and workflow in the operating room: a costeffectiveness study. Surgery, 139(6), 717-728.

Teich, S.T., \& Faddoul, F.F. (2013). Lean management-the journey from toyota to healthcare. Rambam Maimonides Medical Journal, 4(2), 1-9.

Trakulsunti, Y., \& Antony, J. (2018). Can lean six sigma be used to reduce medication errors in the healthcare sector? Leadership in Health Services, 31(4), 426-433.

Van den Heuvel, J., Does, R.J., \& De Koning, H. (2006). Lean six sigma in a hospital. International Journal of Six Sigma and Competitive Advantage, 2(4), 377-388. 
International Journal of Mathematical, Engineering and Management Sciences

Vol. 6, No. 3, 752-770, 2021

https://doi.org/10.33889/IJMEMS.2021.6.3.045

Walley, P. (2003). Designing the accident and emergency system: lessons from manufacturing. Emergency Medicine Journal, 20(2), 126-130.

Waring, J.J., \& Bishop, S. (2010). Lean healthcare: rhetoric, ritual and resistance. Social Science \& Medicine, 71(7), 1332-1340.

Wolfe, A. (2001). Institute of medicine report: crossing the quality chasm: a new health care system for the 21st century. Policy, Politics, \& Nursing Practice, 2(3), 233-235.

Zheng, C., Dai, M., Zhang, Z., \& Hu, Y. (2016). Intelligent control system of medical shadow-less lamps based on STM32. In 2006: 23rd International Conference on Mechatronics and Machine Vision in Practice (M2VIP) (pp.1-4). IEEE. Nanjing, China.

Zidel, T. (2006). A lean guide to transforming healthcare: how to implement lean principles in hospitals. medical offices, clinics, and other healthcare organizations, [online] Google Books. Quality Press. 